\title{
Punching shear and flexural strengths of ultra high performance concrete slabs
}

\author{
C. Joh, H. Hwang \& B. Kim \\ Korea Institute of Construction Technology, Korea
}

\begin{abstract}
Ultra High Performance Concrete (UHPC), compared to conventional concrete, shows highly improved structural behavior, which makes it possible to design slender, light and durable structures. However, further development of practical design formulas is required to apply UHPC to a structural design. This paper reports the result of two independent punching shear tests of UHPC slabs to estimate the punching strength of UHPC slabs. To recommend the reliable punching shear formula for the design of UHPC slabs, the test results are compared to available punching shear formulas for conventional concrete and UHPC. Also, a detailed comparison between the two tests is made to understand the important factors affecting the structural behavior of UHPC slabs. Based on the results, design considerations for UHPC slabs are recommended.
\end{abstract}

Keywords: UHPC slab, casting procedure, flexural capacity, punching shear.

\section{Introduction}

In general, the design of a slab requires the flexural and the punching shear strengths of the slab. Flexural and punching shear formulas for conventional concrete slabs have been developed based on numerous test results and analytical models. However, the flexural and the punching shear strengths of UHPC slabs are not yet fully developed for practical design, because it is a relatively new building material and the structural behavior of UHPC is different from concrete.

This paper reports the result of two independent punching shear tests of UHPC slabs. First, three slabs made of UHPC developed by the Korea Institute of Construction Technology (KICT) are tested to estimate the punching strength of UHPC slabs (hereafter called the PT test). Then, two slabs, which have the same composition and dimensions as the previously tested UHPC slabs, are 
tested using the same test procedure to confirm the validity of the first test results (hereafter called the $\mathrm{T}$ test). To recommend the reliable punching shear formula for the design of UHPC slabs, the test results are compared to the punching shear formula for UHPC $\left(\right.$ Ductal $\left.^{\circledR}\right)$ proposed by Harris and Robert-Wollmann [1], the ACI punching shear formula [2] for RC slabs, and the general formula for prestressed concrete slabs proposed by Graddy et al. [3]. Also, a detailed comparison between these two tests is made to understand the important factors affecting the structural behavior of UHPC slabs. Based on the results, design considerations for UHPC slabs are recommended.

\section{Punching and flexural strengths of UHPC slabs}

The basic approach to calculate the punching shear strength is to find the equilibrium of forces acting on the assumed diagonal failure plane. The angles of the failure plane are assumed to be about $45^{\circ}$ for RC slabs [2].

Graddy et al. [3] proposed the general formula (eqn 1) to explain the change in the angle of failure plane due to prestressing. They proposed $\theta=38^{\circ}$ for a prestressed concrete slab and this formula reduced to ACI punching shear formula [2] when $\theta=45^{\circ}$ eqn (2).

$$
\begin{aligned}
V_{\text {General }} & =2(a+b+2 d / \tan \theta)(d / \tan \theta) f_{t}, \text { Newton } \\
V_{A C I} & =\left(0.17+0.33 / \beta_{c}\right) \sqrt{f_{c}^{\prime}} b_{0} d \leq 0.33 \sqrt{f_{c}^{\prime}} b_{o} d, \text { Newton }
\end{aligned}
$$

In here, $a=$ the length of loaded area $(\mathrm{mm}) ; b=$ the width of loaded area $(\mathrm{mm}) ; \beta_{c}=$ the ratio of long side to short side of loaded area (the aspect ratio of a loading plate); $d=$ effective depth of a slab $(\mathrm{mm}) ; f_{c}{ }_{c}=$ the compressive strength of concrete $(\mathrm{MPa}) ; f_{t}=$ the tensile strength of concrete $(\mathrm{MPa}) ; b_{0}=$ the perimeter of critical section $(\mathrm{mm}) ; \theta=$ the angle between the assumed failure and horizontal planes.

Harris and Robert-Wollmann [1] proposed a punching shear formula (eqn (3)) for UHPC slabs based on the punching shear test of 12 UHPC $\left(\right.$ Ductal $\left.^{\circledR}\right)$ slabs.

$$
V_{V T}=k_{1} f_{t} \frac{(3 d+c)^{2}-c^{2}}{\sqrt{d}}, \text { kips }
$$

In this equation, $k_{1}=$ empirical constant (determined to be 0.38 ); $c=$ the loading plate dimension (inch); $d=$ effective depth of a slab (inch); $f_{t}=$ the tensile strength of UHPC (ksi).

The flexural strength of the slab can be determined by applying yield line analysis with appropriate failure mechanism. In this paper, eqn (4) is adapted based on the failure mechanism shown in Figure 1. The limiting strain criterion proposed in the MIT report [4] is used to calculate flexural capacity of the cross section of the slab.

$$
P_{Y L}=8 M\left[\frac{l}{w-a}+\frac{w}{l-b}\right]
$$




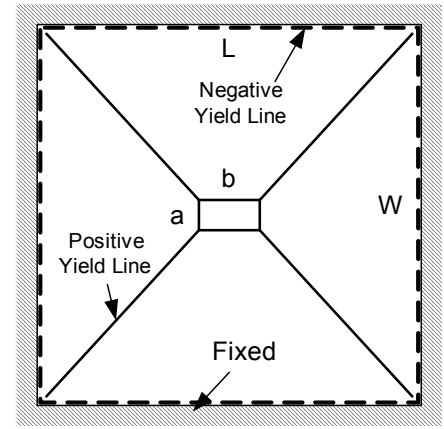

Figure 1: Assumed yield line for fully restrained slabs under rectangular load.
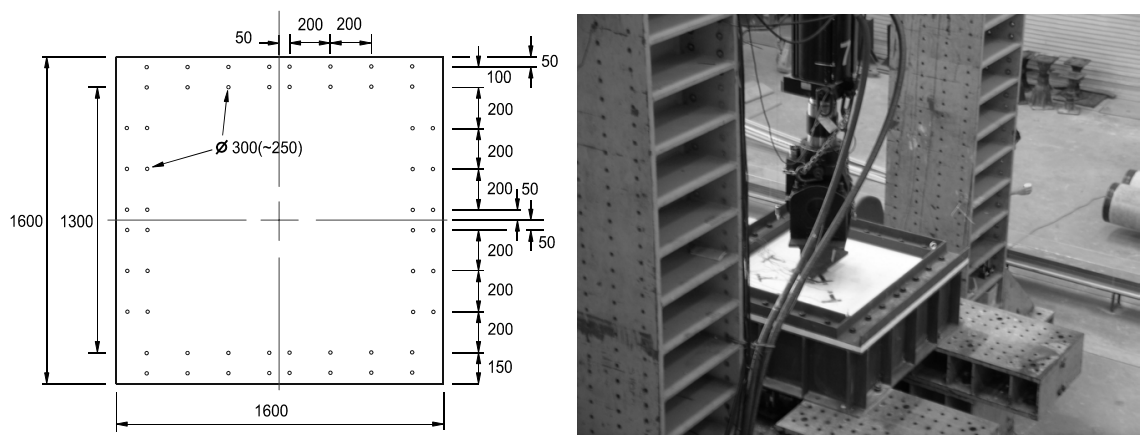

Figure 2: $\quad$ UHPC slab specimen and test setup.

In eqn (4), $M$ is flexural capacity of the section per unit length, and $w$ and $l$ are width and length of the plates, respectively.

It should be noted that punching shear strength depends largely on the cracking (macro crack) strength on the diagonal failure plane of a punching cone rather than on the ultimate tensile strength, because a punching is the brittle failure that occurs on the moment of diagonal cracking. This is important for the punching shear strength of the UHPC slab, because the UHPC in tension usually shows considerable strain hardening after first cracking while conventional concrete does not. On the other hand the flexural capacity of an UHPC section depends largely on the ultimate tensile strength and the post cracking behavior, which is closely related with orientation of steel fibers.

\section{UHPC slab specimens and test setup}

The UHPC slab specimen is a $1600 \mathrm{~mm}$ x $1600 \mathrm{~mm}$ plate with block-outs (fig. 2). The UHPC slab specimens used for PT and $\mathrm{T}$ tests have same composition and dimension (table 1). The tensile strength of the steel fiber is $2500 \mathrm{MPa}$. The length and the diameter of the steel fiber are $13 \mathrm{~mm}$ and $0.2 \mathrm{~mm}$, respectively. 
Table 1: $\quad$ UHPC composition developed by KICT (by weight).

\begin{tabular}{|c|c|c|c|c|c|c|}
\hline $\begin{array}{c}\text { W/ } \\
\text { B }\end{array}$ & Cement & $\begin{array}{c}\text { Silica } \\
\text { fume }\end{array}$ & Sand & $\begin{array}{c}\text { Filling } \\
\text { powder }\end{array}$ & $\begin{array}{c}\text { Super } \\
\text { plasticizer }\end{array}$ & $\begin{array}{c}\text { Steel Fiber } \\
\text { (by volume) }\end{array}$ \\
\hline 0.2 & 1 & 0.25 & 1.1 & 0.3 & 0.016 & $2 \%$ \\
\hline
\end{tabular}

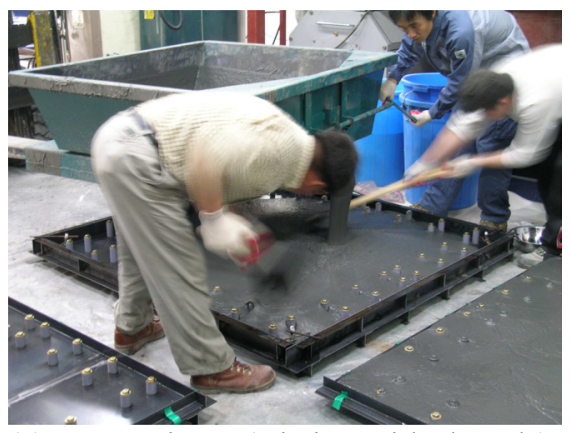

(a) PT specimen (stirring with shovels)

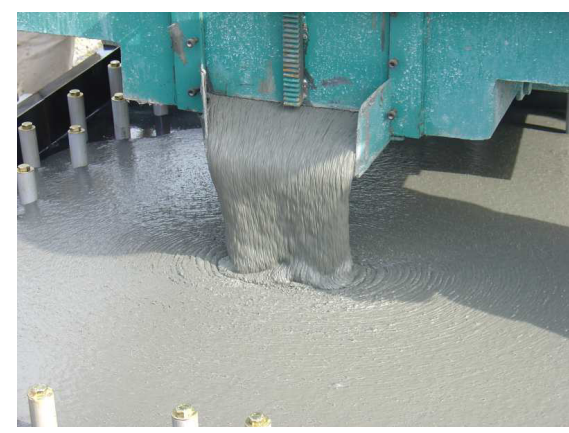

(b) T Specimen (flowing by itself)

Figure 3: $\quad$ Different casting procedures of UHPC slab specimens.

Table 2: $\quad$ Material properties (in average) of UHPC specimens.

\begin{tabular}{|c|c|c|c|c|}
\hline Specimen & $\begin{array}{c}\text { Comp. } \\
\text { Strength }\end{array}$ & $\begin{array}{c}\text { Tensile } \\
\text { Strength }\end{array}$ & $\begin{array}{c}\text { Young's } \\
\text { Modulus }\end{array}$ & $\begin{array}{c}\text { Poisson's } \\
\text { Ratio }\end{array}$ \\
\hline PT Specimens & $194 \mathrm{MPa}$ & $10.5 \mathrm{MPa}$ & $42.9 \mathrm{GPa}$ & 0.164 \\
\hline T Specimens & $211 \mathrm{MPa}$ & $15.3 \mathrm{MPa}$ & $48.1 \mathrm{GPa}$ & 0.156 \\
\hline
\end{tabular}

Though identical UHPC composition is used, the casting procedure and the curing of PT specimens are somewhat different from those of $\mathrm{T}$ specimens. Fabrication for both specimens are supposed to be same, but contractors happen to stir UHPC mixture after pouring it for PT specimens, which is common in casting conventional concrete and introduce the disturbance in the fiber direction (fig. 3(a)). T specimens are done by pouring UHPC mixture near the center and letting it flow (fig. 3(b)). PT specimens are cured at the room $\left(23{ }^{\circ} \mathrm{C}\right)$ for $24 \mathrm{hrs}$ and steam cured at the $90{ }^{\circ} \mathrm{C}$ for $72 \mathrm{hrs}$. T specimens are cured at the field $(7 \sim 18$ ${ }^{\circ} \mathrm{C}$ ) for $24 \mathrm{hrs}$ and steam cured at the $90{ }^{\circ} \mathrm{C}$ for $96 \mathrm{hrs}$. Table 2 shows mechanical properties of UHPC specimens (Tensile strength from the split test).

The test setup is same for both tests. The tested portion of the specimen is $1200 \mathrm{~mm} \times 1200 \mathrm{~mm}$, and the block-out $(200 \mathrm{~mm})$ from each side is used to bolt the edges of the slab down to the test frame to simulate fixed boundary conditions along all edges (fig. 4). The fixed edges on all 4 sides are necessary to the test, because a simply supported slab requires much smaller load to cause a flexural failure. The decrease in flexural failure load would lower the possibility of a punching shear failure. 


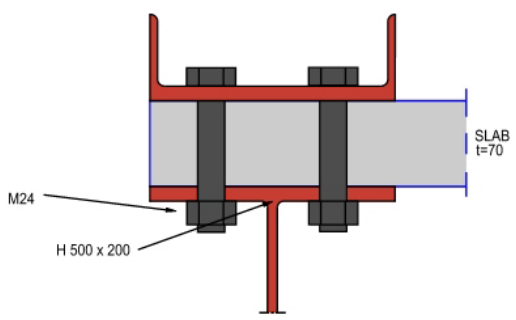

Figure 4: Details of restraint system to simulate fixed boundary conditions.

Table 3: Details of UHPC slab specimens and loading plates.

\begin{tabular}{|c|c|c|c|c|c|c|c|c|}
\hline \multirow{2}{*}{ Specimen } & \multirow{2}{*}{$\begin{array}{c}\mathrm{t} \\
(\mathrm{mm})\end{array}$} & $\begin{array}{c}a \\
(\mathrm{~mm})\end{array}$ & $\begin{array}{c}b \\
(\mathrm{~mm})\end{array}$ & $\beta_{c}$ & $\begin{array}{c}\text { Flexural } \\
\text { (Yield L. })\end{array}$ & $\begin{array}{c}\text { Punching } \\
(\mathrm{ACI})\end{array}$ & $\begin{array}{c}\text { Flexural/ } \\
\text { Punching }\end{array}$ & $\begin{array}{c}\text { Failure } \\
\text { Mode }\end{array}$ \\
\hline PT70-50-50 & 70 & 50 & 50 & 1.5 & 359501 & 155998 & 2.30 & Punching \\
\hline PT70-50-100 & 70 & 50 & 100 & 2.0 & 367672 & 188498 & 1.95 & Punching \\
\hline PT70-50-125 & 70 & 50 & 125 & 2.5 & 372042 & 204747 & 1.81 & Punching \\
\hline \hline T70-50-125 & 70 & 50 & 125 & 2.5 & 529000 & 213500 & 2.47 & Punching \\
\hline T70-40-160 & 70 & 40 & 160 & 4.0 & 536000 & 230500 & 2.32 & Punching \\
\hline
\end{tabular}

The load is applied using a hydraulic actuator, which is attached to the portal loading frame (fig. 2). Up to $50 \%$ of the estimated failure load, the load is applied in a load-controlled mode. Beyond that the load is applied up to failure in a displacement-controlled mode.

Table 3 shows the details of the specimens, loading plates and predicted failure mode. Predicted strengths are calculated based on material properties in table 2 . To increase the possibility of a punching shear failure, relatively small loading plates are used.

\section{Test results}

Fig. 5 shows load-deflection curves from tests. The load-deflection curves can be divided into two groups according to the failure mode. PT specimens from the PT test are failed by typical punching at the center of the slab (fig. 6). On the other hand, $\mathrm{T}$ specimens from the $\mathrm{T}$ test show considerable ductile behavior after reaching flexural strength of the specimen with the given boundary condition. Although $\mathrm{T}$ test is designed to induce a punching failure to confirm punch shear formula obtained from PT test, yield lines are observed clearly in the $\mathrm{T}$ specimens (fig. 7).

The Load-deflection curves for PT specimens show that the displacement is increased with the load approaching a flexural failure, but a punching failure (fig. 6) is occurred first. In general, punching strength is known to proportional to the area of a loading plate and the results of PT specimens show similar trend. 


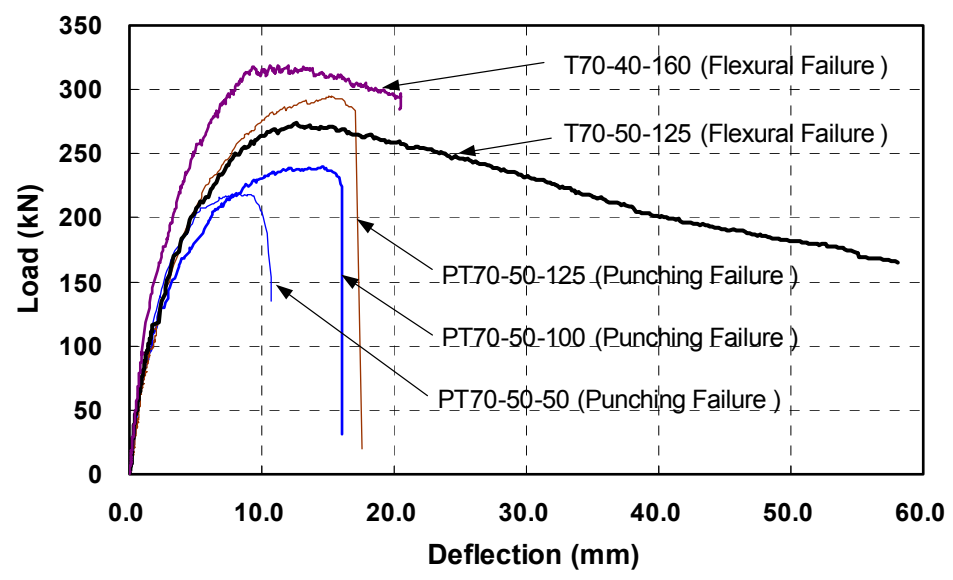

Figure 5: Load-deflection curve for UHPC slab specimen (at the center).
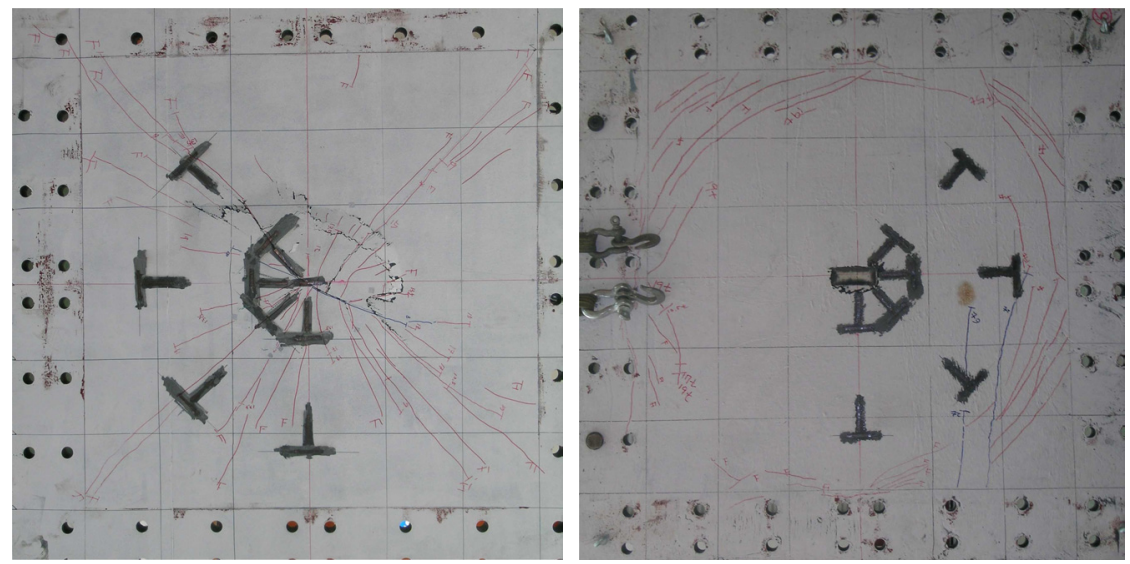

Figure 6: Typical tension (left) and compression (right) sides (PT70-50125).

As shown in fig. 6 left, the cracks on the tensile face begin near the center and radiate out to the edges. The cracks are relatively well distributed and the width of the crack is limited, which means that the steel fibers are holding the crack opening and clear tensile yield lines are not formed yet. The radiating cracks from the center in every direction imply the steel fibers are well distributed. In the compression side, as the load is increased after initial cracking at the center of the tension side, the cracks begin near the corner and propagate along the edges (fig. 6 right).

On the other hand, $\mathrm{T}$ specimens are able to sustain a reduced load while continuing to deform after the peak load. The behavior of the $\mathrm{T}$ specimens is 
different from that of the PT specimens. T specimens show clear yield lines on the compression side and the tension side of the specimen (fig. 7). The yield lines are formed during the descending curve. The failure of $\mathrm{T}$ specimens is affected by the flexural behavior.
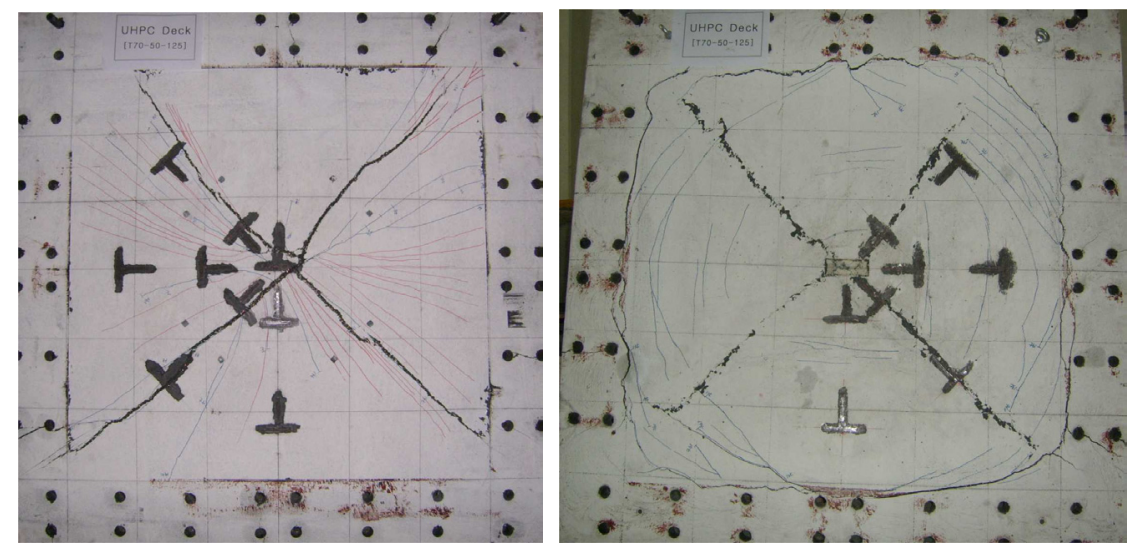

Figure 7: Typical tension (left) and compression (right) sides (T70-50-125).

Most interesting is the comparison between PT70-50-125 and T70-50-125 specimens. Two load-deflection curves are virtually identical up to $250 \mathrm{kN}$ in which radiating diagonal cracks on the tension side and the cracks along the edge on the compression side are formed. After $250 \mathrm{kN}$, the load-deflection curves starts to separate. Though both curves are ascending with the increase in the load, but PT70-5-125 gives steeper one compared to T70-50-125. Beyond 270 $\mathrm{kN}, \mathrm{T} 70-50-125$ reaches the peak load and started to deteriorate, but PT70-50125 is still taking the load until a brittle punching failure occurs.

This difference seems to come from the difference in flexural capacity between two specimens. Fig. 8 shows load-crack width relation of the specimens. As seen in the load-deflection curve, up to $270 \mathrm{kN}$, both specimens shows similar response in cracking, but beyond that load, PT70-50-125 can hold the crack from opening and take more load, while T70-50-125 can not hold the crack from opening. Similar trend can be seen from the load-compressive strain relation in fig. 9. Because PT70-50-125 can hold the crack from opening beyond around $270 \mathrm{kN}$ and T70-50-125 cannot, the compressive strain of PT70-50-125 do not reach the yielding, while the compressive strain of T70-50-125 reaches the yielding.

The main reason for the disagreement between the flexural capacity of PT and $\mathrm{T}$ specimens seems to be the different distribution of fibers in the specimens originated from additional stirring happened to apply to PT specimens during the casting. The stirring UHPC mixture with shovels after pouring it into the mold seems to strengthen strain hardening and post cracking behavior and accordingly the flexural capacity of the section. 


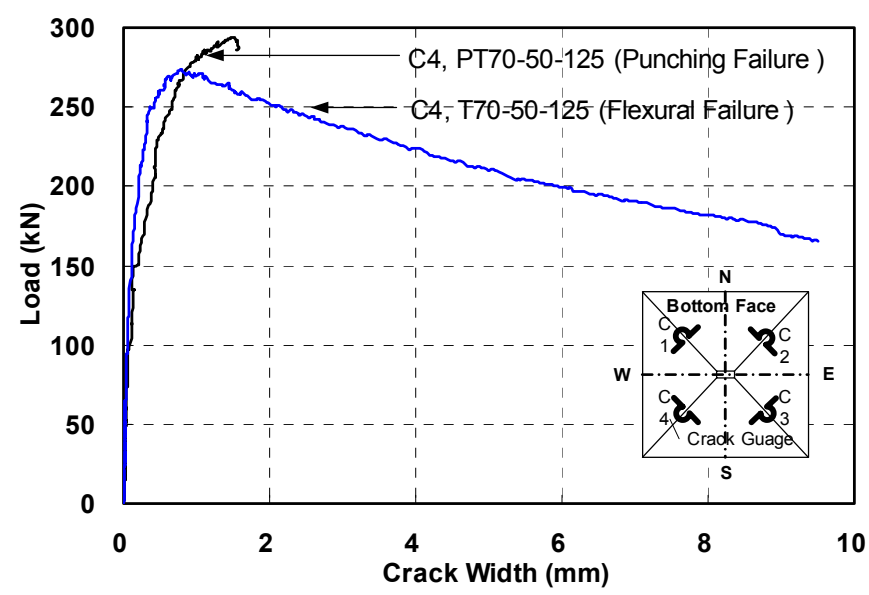

Figure 8: Load-crack width relation.

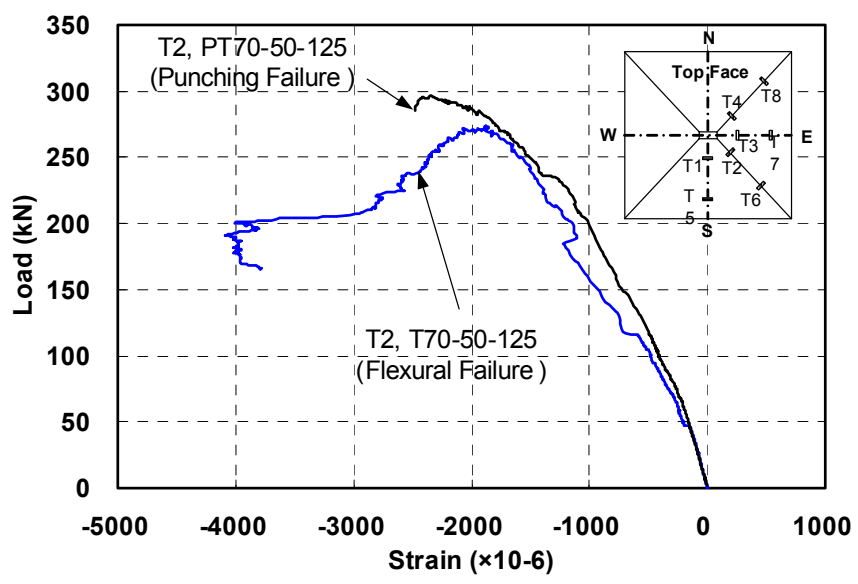

Figure 9: Load-compressive strain relation.

The flexural failure of $\mathrm{T}$ specimens seems to happen because that the casting by pouring UHPC mixture and letting it flow decreases relatively the flexural capacity of $\mathrm{T}$ specimens while the punching shear strength remains more or less unchanged. As mentioned earlier, the punching strength largely depends on the cracking (macro crack) strength rather than ultimate tensile strength and, therefore, relatively unchanged due to the fiber distribution. This difference seems to bring the transition of failure mode from punching to flexural. 


\section{Estimation of punching and flexural strengths}

Table 4 shows the peak loads of the tested specimens, the estimated punching strength and the flexural strength by yield line theory. For the comparison of punching shear formulas, only results from the PT test are used. The results from the $\mathrm{T}$ test are compared with the estimated flexural strength of the slab.

Table 4: $\quad$ Test results and comparison.

\begin{tabular}{|c|c|c|c|c|c|c|c|c|c|}
\hline \multirow{2}{*}{$\begin{array}{c}\text { Specimen } \\
(\mathrm{kN})\end{array}$} & \multirow{2}{*}{$\begin{array}{l}V_{\text {exp }} \\
\text { (1) }\end{array}$} & \multirow{2}{*}{$\begin{array}{l}\mathrm{V}_{\mathrm{ACI}} \\
(2)\end{array}$} & \multirow{2}{*}{$\begin{array}{l}V_{\text {Gen }} \\
(3)\end{array}$} & \multirow{2}{*}{$\begin{array}{l}\mathrm{V}_{\mathrm{VT}} \\
(4)\end{array}$} & \multirow{2}{*}{$\begin{array}{l}P_{Y L} \\
(5)\end{array}$} & \multicolumn{4}{|c|}{ Predicted/Test } \\
\hline & & & & & & $(2) /(1)$ & $(3) /(1)$ & $(4) /(1)$ & $(5) /(1)$ \\
\hline PT70-50-50 & 218.7 & 156.0 & 232.3 & 156.6 & 359.5 & 0.71 & 1.06 & 0.72 & - \\
\hline PT7-50-100 & 239.5 & 188.5 & 273.9 & 181.9 & 367.7 & 0.79 & 1.14 & 0.76 & - \\
\hline PT7-50-125 & 296.7 & 204.7 & 294.7 & 194.5 & 372.0 & 0.69 & 0.99 & 0.66 & - \\
\hline & \multicolumn{5}{|c|}{ Average: } & 0.73 & 1.06 & 0.71 & - \\
\hline T70-50-125 & 273.9 & - & - & - & 529.0 & - & - & - & 1.93 \\
\hline \multirow[t]{2}{*}{ T70-40-160 } & 323.5 & - & - & - & 536.0 & - & - & - & 1.66 \\
\hline & \multicolumn{5}{|c|}{ Average: } & - & - & - & 1.80 \\
\hline
\end{tabular}

(1) Experimental strength; (3) eqn (1) with $38^{\circ}$.

ACI punching formula [2] gives $73 \%$ of actual punching strength in average, which is relatively good prediction considering that this formula is for practical design and gives approximately $70 \%$ of actual punching strength for conventional RC slabs.

The general formula [3] slightly overestimated the actual strength but very close to the actual value. The failure angle lower than $45^{\circ}$ can be explained by the arching action from the fixed boundary. More test results with different conditions are needed to find reliable failure angle for practical use.

Modified ACI318-05 breakout strength with $k_{l}=0.38$ shows similar accuracy to the result of ACI punching formula. However, it should be noted that this formula gave $101 \%$ of actual strength for UHPC (Ductal ${ }^{\circledR}$ ) slabs test by Harris and Robert-Wollmann [1].

Overestimation of flexural strength by yield line theory is probably due to assuming constant tensile stress after first cracking in limiting strain criterion [4]. Since the post-cracking behavior of UHPC largely affects the flexural capacity of an UHPC section, more studies should be done to find better analytical models of flexural strength of the UHPC slab. 


\section{Summary and future research}

Based on the limited test results and analyses, the following comments can be made:

- During the casting of UHPC, the slight variation might affect the fiber distribution, which results in unexpected change in flexural capacity. This must be considered in the design process of UHPC structures.

- The realistic post cracking behavior of UHPC should be considered to estimate the flexural capacity of an UHPC section.

- ACI punching shear formula for RC slabs predicts the punching strength of UHPC slabs reasonably compared to its prediction for RC slabs.

- The general formula with a $38^{\circ}$ failure angle gives a good prediction of punching strength of UHPC slabs with the boundary condition used in the test. However, more test results with different conditions are needed to find the reliable failure angle for practical use.

\section{Acknowledgement}

This research was developed in the context of the research project "Hybrid Cable Stayed Bridge 2020" financed by KICT. The support for this project is gratefully acknowledged.

\section{References}

[1] Harris, D. K., Robert-Wollmann, C. L. Characterization of the Punching Shear Capacity of Thin Ultra-High Performance Concrete Slabs, Report No. VTCR 05-CR26, Virginia Polytechnic Institute \& State University, 2005.

[2] ACI; Building Code Requirements for Structural Concrete and Commentary (ACI318M-05). 2005.

[3] Graddy J. C., Kim, J.; Whitt, J. H., Burns, N. H., Klingner, R. E. PunchingShear Behavior of Bridge Decks under Fatigue Loading. In: ACI Structural Journal, Vol 99, No. 3, pp.257-266, 2002.

[4] Park, H., Ulm, F-J., Chuang, E. Model-Based Optimization of Ultra High Performance Concrete Highway Bridge Girders, CEE Report R03-01, Massachusetts Institute of Technology, Cambridge, MA, 2003. 